\title{
Low Hypodiploid Acute Lymphoblastic Leukemia with Burkitt-like Morphology
}

\author{
Katsuya Yamamoto, Kimikazu Yakushijin, Hiroshi Matsuoka and Hironobu Minami \\ Key words: acute lymphoblastic leukemia (ALL), low hypodiploidy, Burkitt-like morphology
}

(Intern Med 54: 2955, 2015)

(DOI: 10.2169/internalmedicine.54.5240)
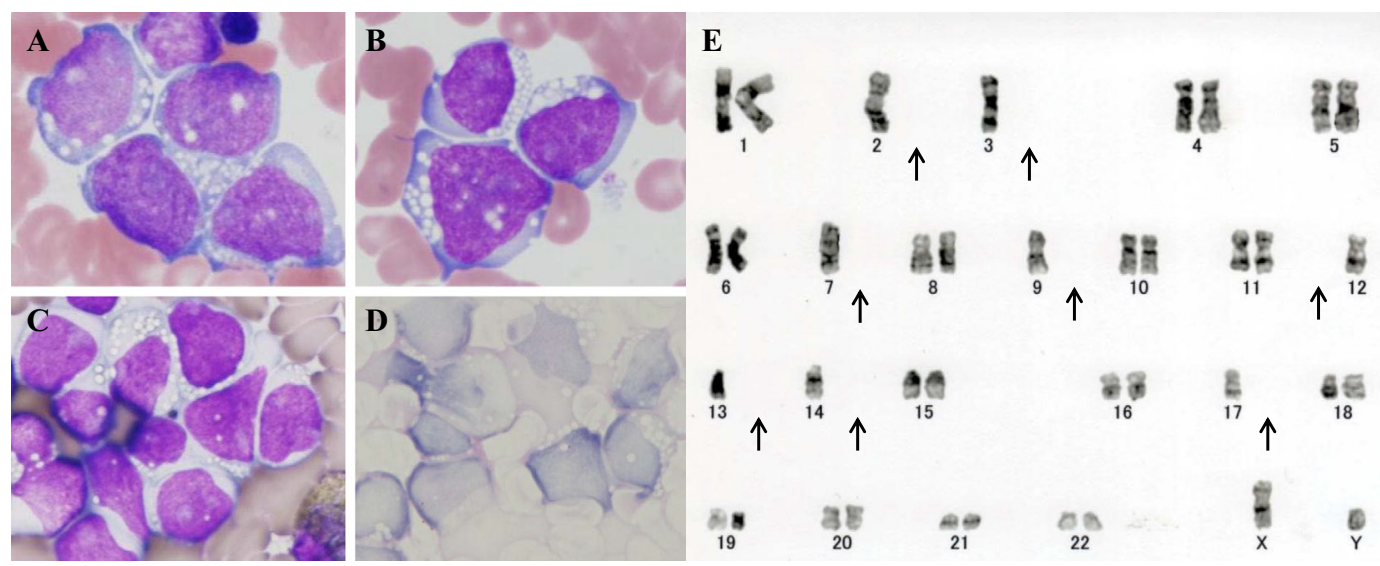

Picture.

A 73-year-old man was admitted to our hospital because of fever. The patient's peripheral blood values were: hemoglobin $144 \mathrm{~g} / \mathrm{L}$, platelets $140 \times 10^{9} / \mathrm{L}$ and leukocytes $2.6 \times 10^{9} /$ $\mathrm{L}$ with $5 \%$ blasts. The bone marrow was normocellular and contained $67.2 \%$ blasts, which exhibited round nuclei with fine nuclear chromatin, basophilic cytoplasm, and many vacuoles (Picture A, B). These blasts were negative for myeloperoxidase activity and the periodic acid-Schiff stain (Picture C, D). An immunophenotyping assay revealed the blasts to be positive for CD10, CD19, CD20, CD34, and HLA-DR. A chromosome analysis demonstrated 38,XY,-2, $-3,-7,-9,-12,-13,-14,-17[6] / 38, \mathrm{sl},-16,+\operatorname{mar} 1[2] / 37, \mathrm{sl}, \operatorname{add}(4)$ (q21),-5, add(11)(p11.2),-22,+mar1[1]/46,XY[11] (Picture E). Therefore, a diagnosis of B-lymphoblastic leukemia/lymphoma with hypodiploidy was made.

The incidence of low hypodiploidy (33-39 chromosomes) was $0.40 \%$ of all patients with acute lymphoblastic leukemia
(ALL), and the median age was 15 years (1). Accordingly, low hypodiploidy is an extremely rare cytogenetic event in an older patient with ALL. Our findings, in conjunction with those of another case (2), suggest that there might be a possibility that leukemic cells with low hypodiploidy could be associated with a Burkitt-like morphology.

The authors state that they have no Conflict of Interest (COI).

\section{References}

1. Harrison CJ, Moorman AV, Broadfield ZJ, et al. Three distinct subgroups of hypodiploidy in acute lymphoblastic leukaemia. $\mathrm{Br} \mathbf{J}$ Haematol 125: 552-559, 2004.

2. Duployez N, Debarri H, Fouquet G. Mixed phenotype acute leukaemia with Burkitt-like cells and positive peroxidase cytochemistry. Br J Haematol 163: 148, 2013.

Division of Medical Oncology/Hematology, Department of Medicine, Kobe University Graduate School of Medicine, Japan Received for publication February 27, 2015; Accepted for publication March 25, 2015

Correspondence to Dr. Katsuya Yamamoto, kyamamo@med.kobe-u.ac.jp

(C) 2015 The Japanese Society of Internal Medicine Journal Website: http://www.naika.or.jp/imonline/index.html 